\title{
Discharge Against Medical Advice in Traumatic Brain Injury: Follow-Up and Readmission Rate
}

\author{
Judith Marcoux, Mohammad Alkutbi, Julie Lamoureux, Mitra Feyz, \\ Rajeet S. Saluja, Elaine de Guise
}

\begin{abstract}
Background: Patients who leave hospital against medical advice (AMA) may be at risk of adverse health outcomes, medical complications, and readmission. In this study, we examined the characteristics of patients who left AMA after traumatic brain injury (TBI), their rates of follow-up visits, and readmission. Methods: We retrospectively studied 106 consecutive patients who left the tertiary trauma center AMA (1.8\% of all admitted patients with a TBI). Preinjury health and social issues, mechanism of injury, computed tomography findings, and injury markers were collected. They were correlated to compliance with follow-up visits and unplanned emergency room (ER) visits and readmission rates. Results: The most prevalent premorbid health or social-related issues were alcohol abuse (33\%) and assault as a mechanism of trauma (33\%). Only 15 (14.2\%) subjects came to follow-up visit for their TBI. Sixteen (15.1\%) of the 106 subjects had multiple readmissions and/or ER visits related to substance abuse. Seven (6.6\%) had multiple readmissions or ER visits with psychiatric reasons. Those patients with multiple readmissions and ER visits showed in higher proportion preexisting neurological condition $(p=0.027)$, homelessness $(p=0.012)$, previous neurosurgery $(p=0.014)$, preexisting encephalomalacia $(p=0.011)$, and had a higher ISS score $(p=0.014)$ than those who were not readmitted multiple times. Conclusions: The significantly increased risks of multiple follow-up visits and readmission among TBI patients who leave hospital AMA are related to a premorbid vulnerability and psychosocial issues. Clinicians should target AMA TBI patients with premorbid vulnerability for discharge transition interventions.
\end{abstract}

RÉSUMÉ: Taux de visite de suivi et de réhospitalisation chez des patients atteints d'une lésion cérébrale traumatique qui quittent l'hôpital contre avis médical. Contexte: Les patients qui quittent l'hôpital contre avis médical (CAM) sont à risque d'encourir des problèmes de santé, des complications médicales et d'être réhospitalisés. Dans cette étude, nous examinons les caractéristiques des patients qui ont quitté l'hôpital CAM suite à une lésion cérébrale traumatique (LCT) ainsi que le taux de visite de suivi et de réhospitalisation. Méthodologie: Nous avons étudié rétrospectivement les dossiers de 106 patients consécutifs qui ont quitté CAM un centre de soins tertiaires en traumatologie, soit 1,8\% de tous les patients admis suite à une LCT. Nous avons colligé les problèmes socio-sanitaires, le mécanisme de la blessure, les constatations à la tomodensitométrie et les marqueurs de la blessure. Nous les avons corrélés à la fidélité aux visites de suivi, aux visites non planifiées au service des urgences et au taux de réhospitalisation. Résultats: Les problèmes les plus fréquents concernant la santé ou la situation sociale étaient l'abus d'alcool (33\%) et l'agression comme cause du traumatisme (33\%). Seulement 15 des sujets $(14,2 \%)$ se sont présentés à la visite de suivi pour leur LCT. Seize des 106 sujets $(15,1 \%)$ ont été réhospitalisés et/ou se sont présenté au service des urgences à plusieurs reprises pour consommation de drogues. Sept (6,6\%) ont été réhospitalisés ou se sont présentés au service des urgences pour des problèmes psychiatriques. Les patients qui ont été réhospitalisés et qui se sont présentés au service des urgences à plusieurs reprises présentaient une proportion plus élevée de problèmes neurologiques préexistants $(\mathrm{p}=0,027)$, d'itinérance $(\mathrm{p}=0,012)$, de neurochirurgie antérieure $(\mathrm{p}=0,014)$, d'encéphalomalacie préexistante $(\mathrm{p}=0,011)$ et l'indice de gravité de la blessure était plus élevé $(\mathrm{p}=0,014)$ chez eux que chez ceux qui n'ont pas été réhospitalisés à plusieurs reprises. Conclusions: Chez les patients atteints d'une LCT qui quittent l'hôpital CAM, les risques significativement élevés de multiples visites de suivi et de réhospitalisation sont reliés à une vulnérabilité prémorbide et à des problèmes psychosociaux. Les cliniciens devraient cibler ces patients présentant une vulnérabilité prémorbide afin de leur fournir un appui à leur sortie de l'hôpital.

Keywords: Traumatic brain injury, doctor-patient relationship, head trauma, patient safety, quality of care, follow-up visits, readmission, discharge against medical advice, Level 1 trauma centre, outcome

doi:10.1017/cjn.2016.241

Can J Neurol Sci. 2017; 44: 311-317

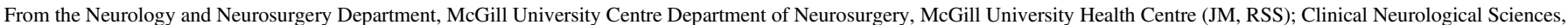
Western University, London, Ontario (MA); Baptist Health South Florida (JL); Traumatic Brain Injury Program, McGill University Health Centre (MF); Department of Psychology, University of Montreal Centre de recherche interdisciplinaire en réadaptation du Montréal métropolitain (CRIR) Research Institute-McGill University Health Center (EdG).

Received July 2, 2015. Final Revisions Submitted February 16, 2016. Date of Acceptance February 16, 2016.

Correspondence to: Judith Marcoux, Department of Neurosurgery, Montreal General Hospital, McGill University Health Centre, 1650 Cedar Ave, Room L7-516, Montreal, Quebec, Canada, H3G 1A4.

Email: judith.marcoux@mcgill.ca 
Discharge against medical advice (AMA) occurs when a patient chooses to leave the hospital setting when treatments or care are still recommended by the treating team. These patients risk their wellbeing, expose themselves to medical complications, and can cause frustration for the treating team involved in health care delivery. When patients are hospitalized and are considering discharge AMA, the medical team should explain risks associated with a premature discharge and are obligated to obtain informed consent with regards to the risk disclosure. ${ }^{1,2}$ Moreover, comprehensive evaluation of the patient's ability to make informed decision should also be considered by the team before asking a patient to sign the release. Although discharge AMA may reflect a failure to reach consensus between the medical team and patient regarding the importance to continue treatments or care, the team is often very concerned that these patients may be at risk to expose themselves to potentially serious health consequences. However, despite the existing literature on the fact that this situation represents approximately $1 \%$ to $2 \%$ of all hospital discharges, ${ }^{3}$ very little knowledge on the adverse consequences of discharge AMA currently exists, especially following traumatic brain injury (TBI). More information on the consequences of discharge AMA following TBI is crucial and may eventually be used to improve communication with these patients who decide to leave AMA by providing them with more accurate information.

In Canada, more than 25,000 patients were discharged AMA in 2013, which corresponds to $1.3 \%$ of all hospitalized patients in Canada. ${ }^{4}$ Previous studies have determined characteristics of patients who are at risk for discharge AMA. In most of the literature, a higher rate of discharge was associated with socioeconomic class, male sex, younger age, insurance status, psychiatric conditions, history of discharge AMA, and substance abuse. ${ }^{5-8}$ In the TBI population, previous studies have shown that between $0.93 \%$ and $2.84 \%$ of TBI patients, from acute care to rehabilitation settings, discharged themselves AMA. ${ }^{9-11}$ Similar patient's characteristics have been reported in the TBI population. In these cases, younger age, unemployment, alcohol/ drug abuse history, intentional injuries (self-inflicted and otherinflicted injury versus unintentional injury), and homelessness were found to be significant predictors for discharge AMA after TBI. ${ }^{10-15}$

Several adverse consequences have been associated to discharge AMA, such as medical and psychosocial complications, frequent readmissions and higher mortality, regardless of the underlying medical reason for admission., ${ }^{5,16-22}$ However, mortality rates following AMA discharge have been limited to short term only. ${ }^{7,13,23}$ A Canadian study done by Hwang and colleagues who compared AMA patients with a control group of patients who leave upon medical recommendation has shown that patients who left AMA were much more likely than the control patients to be readmitted within 15 days. There was no difference among groups in the readmission rate in the following 75 days. Among the patients who left AMA, being male and having a history of alcohol abuse were significant predictors of readmission within 15 days. ${ }^{18}$ An increase of readmission rate within the first 30 days and with a related diagnosis was also reported in HIV-positive patients leaving AMA in comparison with a group formally discharged. ${ }^{16}$ Another study conducted by Choi and colleagues $^{13}$ found that patients discharged AMA were more likely to be readmitted than those who were formally discharge ( $25.6 \%$ vs $3.4 \%$ ) within 14 days with a related diagnosis. Within 1 year, those patients were more likely to be readmitted multiple times or being at higher risk of mortality $(6.7 \%$ vs $2.4 \%, \mathrm{p}=0.01)$ than the formally discharged group. ${ }^{13}$

To our knowledge, however, no studies have yet explored the rate of follow-up visits or readmission in TBI patients who discharge AMA. No predictive variables of medical visits or readmission have been identified in the TBI population. Thus, the objectives of this study were to (1) identify the characteristics and outcomes of TBI patients who leave a tertiary trauma center AMA, (2) identify the rate of follow-up visits and readmission of TBI patients who discharge themselves AMA, and (3) identify predictive factors of TBI patients who come back to the emergency room (ER) or are readmitted following AMA discharge.

\section{MethodS}

\section{Subjects}

All patients $(\mathrm{n}=5778)$ admitted between 2000 and 2011 with a diagnosis of TBI to the Montreal General Hospital, an adult tertiary (level 1) trauma centre, were considered for this retrospective study. The Montreal General Hospital TBI Database and the Trauma Registry Database were used to identify all patients who were discharged from the hospital AMA. Patients evaluated at the ER and discharged AMA from the ER but not admitted to the hospital were not captured by the database, and therefore excluded from the study. In total, 106 patients were identified. The McGill University Health Centre Ethics Review Board and the Director of Professional Services approved this study and the informed consent requirement was waived.

\section{Discharge Protocol}

All admitted patients with a TBI were evaluated and followed by a multidisciplinary team of health professionals as well as the treating physician. Patients were deemed ready for discharge when they were medically cleared and when their behavioural and cognitive functioning were appropriately safe as formally evaluated by a team composed of a physiotherapist, occupational therapist, neuropsychologist, speech therapist, and social worker. All patients were offered at least one medical follow-up visit, either at the neurosurgery clinic with a follow-up computed tomography (CT) scan on the same day of the appointment if the admission CT scan had intracranial bleed, or at the TBI clinic if the CT scan was negative. Follow-up appointments were given within 2 to 6 weeks of discharge and both clinics and the CT scanner were all located at the same hospital where patients had been admitted. No patient is referred to his local hospital or his family physician for that first appointment. Even when leaving AMA, patients were offered follow-up appointments.

\section{Data Collected}

Hospital charts, the TBI database, and the trauma registry database were reviewed to collect demographic data (age, gender, marital status, level of education) and injury related data (Glasgow Coma Scale score on admission, Injury Severity Score (ISS), ${ }^{24}$ isolated TBI versus polytrauma, mechanism of injury). Premorbid illnesses and health- or social-related issues were also collected (including alcohol abuse, homelessness, dementia, intellectual deficit, psychiatric conditions, geriatric profile, preexisting neurological condition (e.g. previous stroke, tumor, neurological degenerative disorders, dementia), behavioural problems, legal 


\section{Table 1: Patients characteristics}

\begin{tabular}{l|c}
\hline $\begin{array}{l}\text { Age (mean } \pm \text { SD) } \\
\text { (range), years }\end{array}$ & $\begin{array}{c}42.9 \pm 15.5 \\
18-94\end{array}$ \\
\hline Male gender (\%) & 91.5 \\
\hline $\begin{array}{l}\text { GCS (mean } \pm \text { SD) } \\
\text { (range) }\end{array}$ & $\begin{array}{c}12.9 \pm 2.9 \\
3-15\end{array}$ \\
\hline $\begin{array}{l}\text { ISS (mean } \pm \text { SD) } \\
\text { (range) }\end{array}$ & $\begin{array}{c}21.4 \pm 8.8 \\
5-45\end{array}$ \\
\hline CT with traumatic lesion (\%) & 77.4 \\
\hline Mechanism of trauma (\%) & 42.5 \\
\hline Fall & 33 \\
\hline Assault & 23.6 \\
\hline Motor vehicle accident & 0.9 \\
\hline Suicide attempt & 0 \\
\hline Work-related & \\
\hline
\end{tabular}

$\mathrm{CT}=$ computed tomography; GCS $=$ Glasgow Coma Scale score; ISS = Injury Severity Score; SD = standard deviation.

issues, or assault as a mechanism of trauma. The length of stay in hospital was also recorded, as well as the extended Glasgow Outcome Scale score (GOSE) ${ }^{25}$ at the time of discharge, which was given by a consensus of the multidisciplinary team caring for the patient.

All CT scans done on presentation were reviewed to collect the following information: presence of an intracranial traumatic lesion, the location (which lobe for intraparenchymal lesion; the location at convexity, tentorial, interhemispheric, posterior fossa for extra axial collections), the nature of the lesion (contusion, subarachnoid haemorrhage, subdural, epidural), and if it was focal or diffuse.

\section{Outcome Measures}

The primary outcome measures that we examined were: (1) the number of patients who returned for scheduled follow-up (related to their TBI or other injuries); (2) the likelihood of suffering another traumatic event, another TBI, or having multiple visits to the ER, or being readmitted to the hospital; and (3) the reasons for visits to ER and readmissions to hospital.

\section{Statistics}

Descriptive statistics were reported for all variables as means, standard deviations, and ranges for numerical variables, and percentages for categorical data. Chi-square tests were done to identify which patient characteristics increased the risk for missed follow-up, multiple visits to the ER, and hospital readmission. To identify the combinations of determinants of risk for missed follow-up, multiple visits to ER, and hospital readmission, we ran backward multiple logistic regressions with a value of $p>0.05$ for removal of independent variables from the model.

All tests were done using Stata 12.1 (StataCorp) and the level of significance was set at $\mathrm{p}<0.05$ for all tests except when specified otherwise in the text.

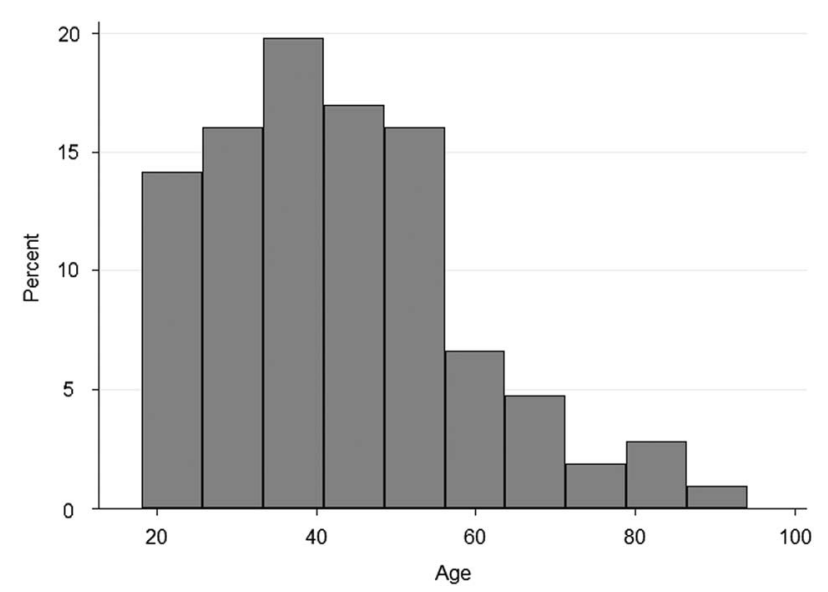

Figure 1: Distribution of age $(n=106)$.

\section{RESUlTS \\ Demographic Data}

A total of 106 patients admitted with TBI left AMA during the study period, which represents $1.8 \%$ of all admitted patients with a TBI (see Table 1 for the patients' sample demographic data). The majority of the subjects were male. The distribution of age was slightly asymmetric as shown in Figure 1.

The level of education achieved was unknown for the majority of the sample $(79.3 \%)$, either because the patients left before this information could be collected or because patients declined to provide this information. For the group of patients in which the level of education was known, the majority had a high school education $(n=15)$, whereas one had an elementary school education, four had a junior college education, and two had a university education.

The marital status was known in a greater proportion $(76 \%)$. The majority of patients were single $(n=68 ; 83 \%)$, whereas nine $(11 \%)$ were married or had a common law spouse, three $(4 \%)$ were divorced or separated, and two (2\%) were widowed.

\section{Premorbid Illnesses and Health or Social-Related Issues}

The majority of the sample $(n=75 ; 71 \%)$ had premorbid illnesses or health or related social issues (Table 2). Twenty-two (21\%) subjects had two or more factors. The most prevalent premorbid health or related social issues were alcohol abuse $(\mathrm{n}=35$; $33 \%)$ and assault as a mechanism of trauma $(n=35 ; 33 \%)$. There were also 13 subjects $(12.3 \%)$ with preexisting cerebral conditions. Six of these $13(46.2 \%)$ had a previous neurosurgery, three (23.1\%) had preexisting encephalomalacia, four $(30.8 \%)$ had global volume loss, two (15.4\%) had old hypodensities, and one $(7.7 \%)$ had white matter chronic ischemic changes.

\section{Injury-Related Data}

The Glasgow Coma Scale score at admission, after resuscitation, was 15 for the majority $(n=64,60 \%)$ of patients and the median was 14 (see Table 1 for details and Figure 2 for the complete distribution in the sample). The ISS was more symmetrically distributed (Figure 3 and Table 1). The CT scan on admission had at least one intracranial traumatic lesion in 82 patients $(77.4 \%)$. Of those with a traumatic intracranial lesion, $11.0 \%$ had an epidural hematoma, $51.2 \%$ had a subdural 


\section{Table 2: Pretrauma health or social problems}

\begin{tabular}{l|c|r}
\hline Psychosocial comorbidities & $\mathbf{n}$ & \% \\
\hline Alcohol abuse & 35 & 33.0 \\
\hline Neurological condition & 11 & 10.4 \\
\hline Intellectual deficiency & 0 & 0.0 \\
\hline Behavioral problem & 3 & 2.8 \\
\hline Psychiatric problem & 12 & 11.3 \\
\hline Geriatric condition & 1 & 0.9 \\
\hline Dementia & 2 & 1.9 \\
\hline Sensory deficit & 0 & 0.0 \\
\hline Suicide attempt & 1 & 0.9 \\
\hline Legal issues & 0 & 0.0 \\
\hline Homelessness & 7 & 6.6 \\
\hline IVAC & 35 & 33.0 \\
\hline
\end{tabular}

IVAC $=$ indemnisation des victimes d'actes criminels [criminal act victims].

hematoma, $50.0 \%$ had a subarachnoid haemorrhage, $56.1 \%$ had an intracerebral haemorrhage, and $7.3 \%$ had an intraventricular haemorrhage. In addition, of those who had an abnormal CT scan, 56 patients had intraaxial lesions $(68.3 \%), 15.8 \%$ of which had focal involvement; $24.4 \%$ had multifocal involvement; and $28.1 \%$ had diffuse involvement. The remaining 26 patients $(31.7 \%)$ had purely extra-axial involvement. The lesions were localized to specific lobes for $59.8 \%$ of the patients, as follows: $42.7 \%$ had frontal lobe lesions, $31.7 \%$ had temporal lobe lesions, $11.0 \%$ had parietal lobe lesions, and $1.2 \%$ had occipital lobe lesions. Furthermore, for those with an extra-axial lesion, $15.9 \%$ of the lesions were located along the convexity, $19.5 \%$ were located in the interhemispheric space, $22.0 \%$ were adjacent to the tentorium cerebelli, and $12.2 \%$ were in the posterior fossa. Only six $(5.7 \%)$ patients required a neurosurgical intervention.

\section{Outcomes}

The average ( \pm standard deviation) length of stay in the hospital was $7.2( \pm 9.5)$ with a range from 0 to 58 days. The length of stay was asymmetric as expected, with more than $60 \%$ leaving within the first 5 days. The distribution of duration of stay in days is given in Figure 4. For the GOSE at discharge, there were

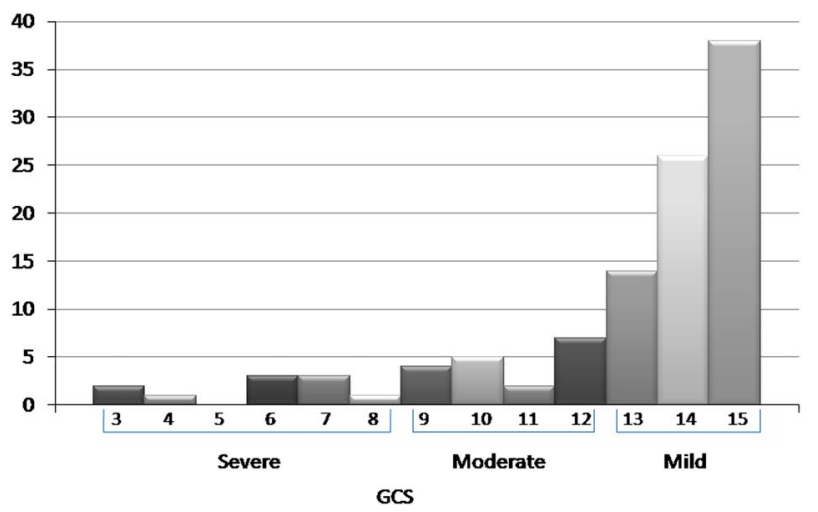

Figure 2: Distribution of GCS scores $(n=106)$.

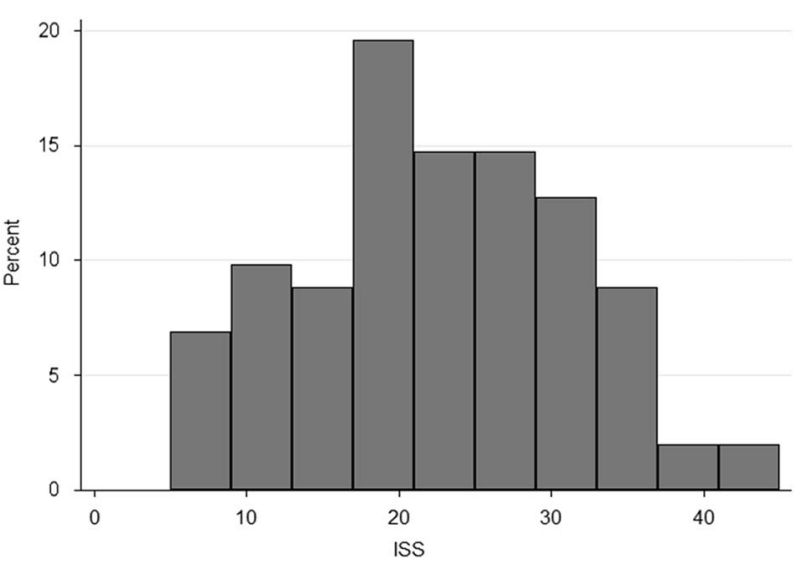

Figure 3: Distribution of ISS $(n=102)$

10 missing values $(9.4 \%)$ because patients left before a comprehensive assessment could be done to determine their level of functioning. Of the 96 subjects with documented GOSE, on a total score of 7, two (2.1\%) had upper severe disability (score of 3), 21 $(21.9 \%)$ had lower moderate disability (score of 4$), 64(66.7 \%)$ had upper moderate disability (score of 5), and nine $(9.4 \%$ ) had lower good recovery (score of 6).

\section{Follow-Up Visits}

Only $15(14.2 \%)$ subjects came back to a follow-up visit for their TBI. Forty-six of the 106 subjects $(43.4 \%)$ had at least one follow-up visit of any sort. A majority of subjects did not have a readmission (70 of 106; 66.0\%). Sixteen $(15.1 \%$ ) of the 106 subjects had multiple readmissions and/or ER visits related to substance abuse. Seven (6.6\%) had multiple readmissions or ER visits for psychiatric issues. Eight (7.5\%) subjects had readmissions or ER visits for seizures. Eleven (10.4\%) subjects had visits for other medical reasons. Seven (6.6\%) subjects had readmissions for unknown reasons, and seven $(6.6 \%)$ had readmissions for new TBI or other trauma.

Seven of 106 subjects $(6.6 \%)$ leaving AMA were seen in outpatient rehabilitation. Those seen in outpatient rehabilitation showed higher proportion of females $(28.6 \%$ vs $7.1 \%$ )

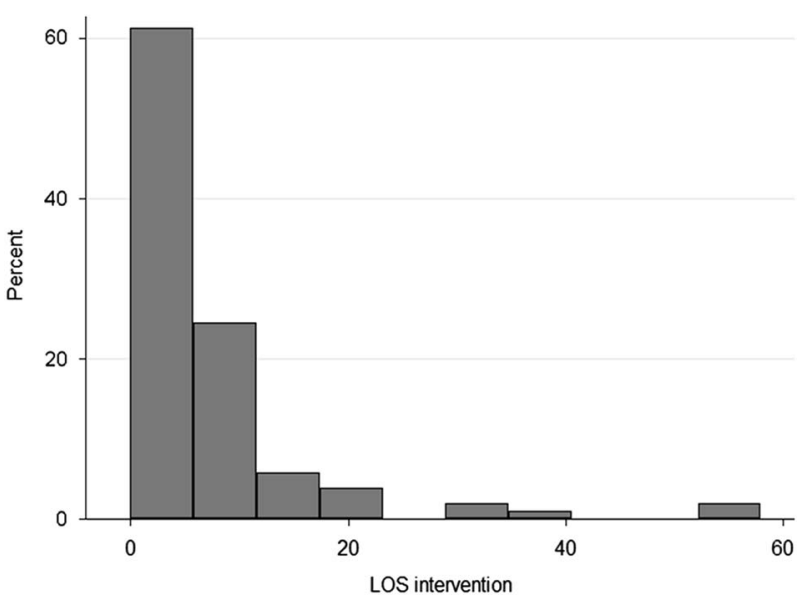

Figure 4: Distribution of length of stay in days $(n=106)$. 
$\left(\chi_{1 \mathrm{df}}^{2}=3.890 ; \mathrm{p}=0.049\right)$, suicide attempt $(20.0 \%$ vs $0.0 \%)$ $\left(\chi_{1 \mathrm{df}}^{2}=10.586 ; \mathrm{p}=0.003\right)$, and epidural bleed $(28.6 \%$ vs $7.1 \%)$ $\left(\chi_{1 \mathrm{df}}^{2}=3.890 ; \quad \mathrm{p}=0.049\right)$ than those without outpatient rehabilitation.

\section{Follow-Up Compliance Predictors}

Suicidal attempt as the mechanism of trauma was associated with a significantly higher likelihood to come back for the TBI follow-up $\left(\chi_{1 \mathrm{df}}^{2}=6.109 ; \mathrm{p}=0.013\right)$, but it represents only one patient. None of the other factors was associated with the compliance or noncompliance of TBI follow-up. Also, none of the factors was associated with the compliance or noncompliance of any follow-up visit, although the presence of an abnormal finding on CT $\operatorname{scan}\left(\chi_{1 \mathrm{df}}^{2}=2.926 ; \mathrm{p}=0.087\right)$ and temporal lobe involvement $\left(\chi_{1 \mathrm{df}}^{2}=3.718 ; \mathrm{p}=0.054\right)$ approached significance for their association with no follow-up. Using the variables that were associated with any type of follow-up at the $p<0.1$ level of significance (assault, positive CT, lesion in the temporal lobe), we ran a multiple stepwise logistic regression to determine which combination, if any, of independent variables were most predictive of the outcome. Only one variable decreased significantly the occurrence of follow-up of any kind: lesion in the temporal lobe $(p=0.023)$. This model has a pseudo- $\mathrm{R}^{2}$ of 0.04 and the sample size used was $\mathrm{n}=106$. Only one of six who required a neurosurgical intervention $(16.7 \%)$ came to the followup appointment, whereas $14(14.0 \%)$ of those who did not have neurosurgery came to follow-up. Therefore, being surgically treated for the TBI did not increase the likelihood of compliance to follow-up $\left(\chi_{1 \mathrm{df}}^{2}=0.033, \mathrm{p}=0.856\right)$. Similarly, $46.0 \%$ of patients who did not have neurosurgery came to their follow-up appointment compared with $66.7 \%$ of those who had neurosurgery $\left(\chi_{1 \mathrm{df}}^{2}=0.970, \mathrm{p}=0.325\right)$. However, it should be kept in mind that the number of patients having had neurosurgery was very small to detect differences in proportion of follow-up.

\section{Predictors of Multiple Readmissions or ER Visits}

Thirty-six of the 106 subjects (34.0\%) had ER visit and/or readmission for any reason and showed higher proportion of homelessness $(23.8 \%$ vs $5.6 \%)\left(\chi_{1 \mathrm{df}}^{2}=4.102, \mathrm{p}=0.043\right)$, diffuse involvement on CT scan $(33.3 \%$ vs $15.7 \%) \quad\left(\chi_{1 \mathrm{df}}^{2}=4.344\right.$, $\mathrm{p}=0.037)$, but lower proportion of unilateral lesions $(22.2 \%$ vs $41.4 \%)\left(\chi_{1 \mathrm{df}}^{2}=3.860, \mathrm{p}=0.049\right)$ than those not seen in ER and/or readmitted for any reason. Fifteen patients (14\%) presented themselves to ER within 30 days of leaving the hospital AMA, three of them for intoxication and the remaining for complaints directly related to their trauma (e.g. headache, need for medication, seizure, wound infection).

Readmission or ER visits for substance abuse was seen in $15.1 \%$ of TBI patients who left AMA. Many factors were associated with multiple readmissions or ER visits for substance abuse. Those patients with multiple readmissions and ER visits for substance abuse showed in higher proportion preexisting neurological condition $(41.7 \%$ vs $13.3 \%)\left(\chi_{1 \mathrm{df}}^{2}=4.883 ; \mathrm{p}=0.027\right)$, homelessness $(33.3 \%$ vs $6.7 \%) \quad\left(\chi_{1 \mathrm{df}}^{2}=6.254 ; \mathrm{p}=0.012\right)$, previous neurosurgery $(18.8 \%$ vs $3.3 \%) \quad\left(\chi_{1 \mathrm{df}}^{2}=6.046\right.$; $\mathrm{p}=0.014)$, preexisting encephalomalacia $(12.5 \%$ vs $1.1 \%)$ $\left(\chi_{1 \mathrm{df}}^{2}=6.407 ; \mathrm{p}=0.011\right)$, and had a higher ISS score $\left(\mathrm{T}_{100 \mathrm{df}}=\right.$ $2.500 ; \mathrm{p}=0.014)$ than those who were not readmitted multiple times.
Seven patients $(6.6 \%)$ had ER visits for repeat trauma and they showed in higher proportion homelessness (40.0\% vs $9.6 \%$ ) $\left(\chi_{1 \mathrm{df}}^{2}=3.909, \mathrm{p}=0.048\right)$, previous neurosurgery $(28.6 \%$ vs $4.0 \%)\left(\chi_{1 \mathrm{df}}^{2}=7.368, \mathrm{p}=0.007\right)$, previous encephalomalacia $(28.6 \%$ vs $1.0 \%)\left(\chi_{1 \mathrm{df}}^{2}=18.059, \mathrm{p}<0.001\right)$, parietal lesions $(28.6 \%$ vs $7.1 \%)\left(\chi_{1 \mathrm{df}}^{2}=3.890, \mathrm{p}=0.049\right)$, and interhemispheric lesions $(42.9 \%$ vs $13.1 \%)\left(\chi_{1 \mathrm{df}}^{2}=4.508, \mathrm{p}=0.034\right)$ than those not readmitted for another trauma. Using the variables that were associated with ER visits or readmission for repeat trauma at the $\mathrm{p}<0.1$ level of significance (presence of homelessness in the complicating factors, previous neurosurgery, encephalomalacia, lesion in the parietal lobe, mass effect and location of the lesion in the interhemispheric area), we ran a multiple stepwise logistic regression to determine which combination of independent variables were most predictive of the outcome. Two variables increased significantly the risk of this type of readmission: encephalomalacia $(\mathrm{p}=0.003)$ and lesion in the parietal lobe $(\mathrm{p}=0.030)$. This model has a pseudo- $\mathrm{R}^{2}$ of 0.23 and the sample size used was $\mathrm{n}=106$.

Furthermore, 16 patients (15.1\%) had recurrent visits to ER for seizures. A history of previous neurosurgery $\left(\chi_{1 \mathrm{df}}^{2}=7.368\right.$, $\mathrm{p}=0.007)$, preexisting neurological condition $\left(\chi_{1 \mathrm{df}}^{2}=5.830\right.$, $\mathrm{p}=0.016)$, or homelessness $\left(\chi_{1 \mathrm{df}}^{2}=3.909, \mathrm{p}=0.48\right)$ were predictive for recurrent visits to ER for seizures in patients who left AMA.

Interestingly, patients who required readmission for medical reasons were more compliant with follow-up visits $(81.8 \%$ vs $38.3 \%)\left(\chi_{1 \mathrm{df}}^{2}=7.616 ; \mathrm{p}=0.006\right)$. Similarly, but to a lesser extent, those who were readmitted for any reason attended followup visits at a higher rate $(58.3 \%$ vs $34.8 \%)\left(\chi_{1 \mathrm{df}}^{2}=5.358\right.$; $\mathrm{p}=0.021)$.

\section{Discussion}

The objectives of this study were to identify the characteristics and outcome of TBI patients who leave a tertiary trauma center AMA as well as rates of follow-up visits and readmission, and to isolate predictive variable factors of TBI patients who need to come back to the ER or be readmitted following AMA discharge.

The present study showed a rate of discharge AMA of $1.8 \%$ amongst admitted TBI patients, which is consistent with the rates reported in the literature for TBI. ${ }^{9-11}$ It also showed that single male patients who present with history of alcohol abuse were representative of the TBI patients who leave AMA; these findings were in accordance with previous studies, ${ }^{5-8}$ including our previous study on the same population. ${ }^{11}$ In addition, one-third of our cohort was involved in an assault. Our institution being in a large urban area, some characteristics such as history of alcohol abuse and assault may be found in a greater proportion in our source population than in a trauma center located in a more rural setting. Some studies have shown that persons with violencerelated TBI are a vulnerable population in acute and rehabilitation care $^{26,27}$ and share common risk factors with psychiatric patients who discharge AMA, such as antisocial, aggressive, or disruptive behaviours. $^{28}$ In fact, intentional injury was also found to be a significant predictor of discharge AMA in acute care settings in a previous study. ${ }^{10}$

Along this line of reasoning, particular behaviour and cognitive profile may be related to the CT abnormalities in our TBI 
patients who leave AMA. Interestingly, specific characteristics observed in the cerebral imaging of those patients with TBI who discharge themselves AMA revealed that a large proportion of these patients had premorbid abnormalities on CT scan as cerebral atrophy, encephalomalacia, chronic ischemic changes, and hypodensities. These cerebral abnormalities revealing a cerebral vulnerability are usually observed in different types of dementia (e.g. alcohol related, vascular, AIDS). ${ }^{29-31}$ Our data also show that, even if a large proportion of our cohort sustained a mild TBI (60\%), the CT scan on admission had at least one intracranial traumatic lesion in three-quarters of the cohort, mainly frontal $(42.7 \%)$ or temporal lesions $(31.7 \%)$. Moreover, $66.7 \%$ of the cohort had upper moderate disability upon discharge, despite all the CT abnormalities and the multiple cognitive effects that the premorbid or traumatic lesions may have on cognitive abilities such as executive functions, memory impairments or disturbed behavior (impulsivity and disinhibition).

All TBI patients in this cohort were competent and informed about adverse effects of AMA discharge as well as risk to leave AMA when they signed the informed consent, but they may have been limited in their ability to comprehend the severity of their medical situations. Our study reveals that TBI patients who leave AMA may be a vulnerable population and the extent of their competency with regards to their ability to provide a truly informed consent for discharge AMA must be evaluated. This cerebral and psychosocial vulnerability is highlighted by the relatively large number of patients $(14 \%)$ who had bounce-back visits to ER and/or readmission within 30 days of leaving AMA.

A high rate of patients (14\%) had bounce-back visits to ER and/or readmission within 30 days of leaving AMA, and this can be seen as poor outcome, even if as a group the patients who left AMA were in a better neurological and function status than those who did not leave AMA. ${ }^{11}$ Furthermore, a total of $15.1 \%$ of TBI patients who left AMA were readmitted because of alcohol intoxication and many factors were associated with multiple readmissions or ER visits such as preexisting neurological condition, homelessness, previous neurosurgery, and preexisting encephalomalacia. Better care and more specific services are needed to assure a close follow-up with this vulnerable population. The intervention provided to this population should be flexible and different ways to intervene with homeless TBI patients should be developed with the help of social services in the community and other services such as shelters.

Results observed from CT scans done on TBI patients discharged AMA showed that the one variable that decreased significantly the occurrence of follow-up of any kind was the presence of a lesion in the temporal lobe. Several studies have shown a relationship between temporal lesions and memory impairments. ${ }^{32}$ It is possible that many of those patients had forgotten their follow-up appointments even if they received a card with all the follow-up information required. Telephone follow-up with these patients and appointment recall may be a practical solution to increase the compliance. Indeed, only $14.2 \%$ of patients who left AMA came to their follow-up appointment for the TBI, which is much lower than the $58 \%$ to $58.6 \%$ follow-up at 1 year and $39.7 \%$ to $42.0 \%$ at 2 years reported in the literature. ${ }^{33}$

Also, $15.1 \%$ had recurring visits to ER for seizures. Posttraumatic seizures are normally not as common, and this high rate could be related to the fact that patients discharged
AMA were also not compliant with a 7-day course of seizure prophylaxis when it was indicated to receive it. Also, the seizure threshold could have been lowered by the intake and/or withdrawal of alcohol soon after discharge, as many patients have alcohol abuse problems. Finally, $12.3 \%$ of the patients had pre-existing cerebral conditions that could have rendered them more susceptible to seizures following a TBI.

This study provides more information to help clinicians target patients who are at risk of leaving AMA and should help to target AMA patients for discharge transition interventions. Further interventions should be provided. They can include telephone follow-ups, home visits, or counseling as needed. In addition, having a more specific profile of patients at risk to be discharged AMA may help to reduce the number of patients who leave before achieving clinical stability. This can be achieved by improving communication style, involving family members or relatives as soon as possible in care decisions or access to social or psychological support services. As a previous study interviewing physicians after a patient left AMA demonstrated that poor communication was contributive to AMA discharge, ${ }^{6}$ perhaps improved communication between medical team, caregiver, patient, and relatives, especially early in the admission, can help decrease the rate of patients leaving AMA.

This study should be considered with some limitations. Because of the retrospective nature of this study, several clinical and social factors are missing. For example, there are holes in the demographic dataset, especially regarding the level of education and the marital status. Mortality rates or follow-up in other medical centers are also unknown. Also, because of the very large sample size of the reference population (5778 patients), we did not collect data on follow-up. No systematic follow-up was done with the 106 TBI patients who discharged themselves AMA. Using CT scan instead of a more detailed technique to detect cerebral abnormalities gives less precision with regards to pre- and posttraumatic lesions than an MRI might provide. However, we still believe that this study would be helpful in better targeting patients at risk as well as providing more information to the patients regarding the risk to have to revisit the ER or to be readmitted following a TBI.

\section{Conclusions}

The significantly increased risks of multiple ER visits and readmission among TBI patients who leave hospital AMA are likely related to a premorbid vulnerability and psychosocial issues. Clinicians should target AMA TBI patients with premorbid vulnerability for discharge transition interventions and starting early intervention strategies after discharge could help in patient compliance with treatment, especially for those who are the most vulnerable.

\section{ACKNOWLEDGMENTS}

We thank the Research Institute of the McGill University Health Center for their support.

\section{Disclosures}

None of the authors has any competing financial interests. 


\section{REFERENCES}

1. Berger JT. Discharge against medical advice: ethical considerations and professional obligations. J Hosp Med. 2008;3:403-8.

2. Farber Post L, Blustein J, Dubler NN. Handbook for health care ethics committees. New York, NY: Johns Hopkins University Press; 2006.

3. Devitt PJ, Devitt AC, Dewan M. Does identifying a discharge as "Against medical advice" confer legal protection? J Fam Pract. 2000;49:224-7.

4. Canadian Institute for Health Information (CIHI). Leaving against medical advice: characteristics associated with self-discharge. Reports CIHI [CIHI Web site]. October 1, 2013. Available from: https://secure.cihi.ca/free_products/LAMA_aib_oct012013_en.pdf. Accessed June 2, 2015.

5. Alfandre DJ. "I'm going home": discharges against medical advice. Mayo Clin Proc. 2009;84:255-60.

6. Brook M, Hilty DM, Liu W, Hu R, Frye MA. Discharge against medical advice from inpatient psychiatric treatment: a literature review. Psychiatr Serv. 2006;57:1192-8.

7. Glasgow JM, Vaughn-Sarrazin M, Kaboli PJ. Leaving against medical advice (AMA): risk of 30-day mortality and hospital readmission. J Gen Intern Med. 2010;25:926-9.

8. Yong TY, Fok JS, Hakendorf P, Ben-Tovim D, Thompson CH, Li JY. Characteristics and outcomes of discharges against medical advice among hospitalised patients. Intern Med J. 2013;43: 798-802.

9. Duñó R, Pousa E, Sans J, Tolosa C, Ruiz A. Discharge against medical advice at a general hospital in Catalonia. Gen Hosp Psychiatry. 2003;25:46-50.

10. Kim H, Colantonio A, Bayley M, Dawson D. Discharge against medical advice after traumatic brain injury: Is intentional injury a predictor? J Trauma. 2011;71:1219-25.

11. de Guise E, LeBlanc J, Dagher J, Lamoureux J, et al. Characteristics of patients with acute traumatic brain injured patients discharged against medical advice in a Level 1 urban trauma center. Brain Inj. 2014;2:1-7.

12. Kim H, Colantonio A. An examination of discharge against medical advice from brain injury inpatient rehabilitation. Brain Inj. 2013;27:325-31.

13. Choi M, Kim H, Qian H, Palepu A. Readmission rates of patients discharged against medical advice: a matched cohort study. Plos One. 2011;6:e24459.

14. Heffernan DS, Vera RM, Monaghan SF, et al. Impact of socioethnic factors on outcomes following traumatic brain injury. J Trauma. 2011;70:527-34

15. Corrigan J, Borgner J, Lamb-Hart G, et al. Problematic substance use identified in the TBI Model Systems national database. The Center for Outcome Measurement in Brain Injury. Available at: http:// tbims.org/combi/subst/index.html. Accessed November 16, 2005.

16. Anis AH, Sun H, Guh DP, Palepu A, Schechter MT, O'Shaughnessy MV. Leaving hospital against medical advice among HIV-positive patients. CMAJ. 2002; 167:633-7.
17. Aliyu ZY. Discharge against medical advice: sociodemographic, clinical and financial perspectives. Int J Clin Pract. 2002;56:325-7.

18. Hwang SW, Li J, Gupta R, Chien V, Martin RE. What happens to patients who leave hospital against medical advice? CMAJ. 2003;168:417-20.

19. Gerbasi JB, Simon RI. Patients' rights and psychiatrists' duties: discharge patients against medical advice. Harv Rev Psychiatry. 2003; 11:333-43.

20. Baptist AP, Warrier I, Arora R, Ager J, Massanari RM. Hospitalized patients with asthma who leave against medical advice: characteristics, reasons, and outcomes. J Allergy Clin Immunol. 2007;119:924-9.

21. Fiscella K, Meldrum S, Barnett S. Hospital discharge against advice after myocardial infarction: deaths and readmissions. Am J Med. 2007; $120: 1047-53$.

22. Jerrard DA, Chasm RM. Patients leaving against medical advice (AMA) from the emergency department-disease prevalence and willingness to return. J Emerg Med. 2011;41:412-7.

23. Southern WN, Nahvi S, Arnsten JH. Increased risk of mortality and readmission among patients discharged against medical advice. Am J Med. 2012;125:594-602.

24. Baker SP, O'Neill B, Haddon W Jr, Long WB. The Injury Severity Score: a method for describing patients with multiple injuries and evaluating emergency care. J Trauma. 1974;14: $187-19$.

25. Jennett B, Snoek J, Bond MR, Brooks N. Disability after severe head injury: observations on the use of the Glasgow Outcome Scale. J Neurol Neurosurg Psychiatry. 1981;44:285-93.

26. Gerhart KA, Mellick DC, Weintraub AH. Violence-related traumatic brain injury: a population-based study. J Trauma. 2003;55: 1045-53.

27. Hanks RA, Wood DL, Millis S, et al. Violent traumatic brain injury: occurrence, patient characteristics, and risk factors from the Traumatic Brain Injury Model Systems project. Arch Phys Med Rehabil. 2003;84:249-54.

28. Windish DM, Ratanawongsa N. Providers' perceptions of relationships and professional roles when caring for patients who leave the hospital against medical advice. J Gen Intern Med. 2008;23:1698-707.

29. Brown WR, Thore CR. Review: cerebral microvascular pathology in ageing and neurodegeneration. Neuropathol Appl Neurobiol. 2011;37:56-74

30. Wilson BG. CT assessment of CNS complications of AIDS. Radiol Technol. 200;73:424-37; quiz 438-40.

31. Román G, Pascual B. Contribution of neuroimaging to the diagnosis of Alzheimer's disease and vascular dementia. Arch Med Res. 2012;43:671-6

32. Meunier M, Barbeau E. Recognition memory and the medial temporal lobe: from monkey research to human pathology. Rev Neurol. 2013;169:459-69.

33. Corrigan JD, Harrison-Felix C, Bogner J, et al. Systematic bias in traumatic brain injury outcome studies because of loss to follow-up. Arch Phys Med Rehabil. 2003;84:153-60. 